\title{
Los exilios venezolanos en México y Costa Rica durante el siglo XX.
}

\author{
Andrés Cervantes Varela \\ Estudiante de Doctorado \\ Instituto de Investigaciones Históricas, \\ Universidad Michoacana de San Nicolás de Hidalgo \\ México
}

\section{Resumen}

El objetivo del presente artículo es esbozar un capítulo de la historia del exilio latinoamericano aún no investigado: la vida y las actividades de los grupos de ciudadanos venezolanos que, entre 1928 y 1935, y entre 1948 y 1958 , fueron opositores o víctimas de los gobiernos que ejercieron el poder nacional respaldados por poderosos intereses económicos nacionales y extranjeros. Estos ciudadanos, como opositores al gobierno, encontraron seguridad y oportunidades al salir de Venezuela,

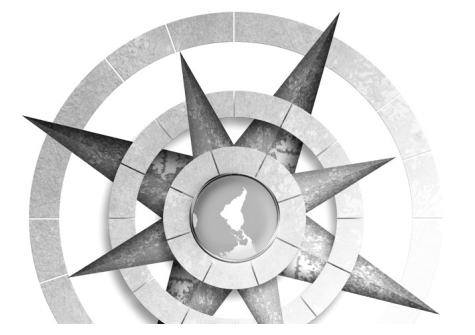

http://dx.doi.org/10.15359/tdna.33-e.8 principalmente en dos países hermanos,

México y Costa Rica. Estos países fueron los mayores receptores y protectores de exiliados latinoamericanos perseguidos por gobiernos autoritarios y entreguistas de la América del siglo Xx.

Palabras clave: exilio venezolano en México, exilio venezolano en Costa Rica, exilio latinoamericano, persecución política en Venezuela, Temas de Nuestra América, Cátedra del Exilio Latinoamericano

\section{Abstract}

This article aims to outline a chapter of the history of Latin American exile that has not been investigated yet: the life and activities of groups of Venezuelan citizens who between 1928 and 1935 and between 1948 and 1958 were opponents or victims of governments which came to national power backed by powerful domestic and foreign economic interests. These citizens, as opponents of 
those governments, found security and opportunities to leave Venezuela mainly towards two countries: Mexico and Costa Rica. México and Costa Rica were the largest recipients and protectors of those Latin American exiles persecuted by authoritarian governments during the twentieth-century.
Keywords: Venezuelan exile in Mexico, Venezuelan exile in Costa Rica, Latin American exile, political persecution in Venezuela, Temas de Nuestra América, Exile Research Group.

\section{Fotografía 1}

Rómulo Gallegos escritor con un grupo de estudiantes venezolanos en el Jardín de los Héroes, Morelia, Michoacán, 1952.

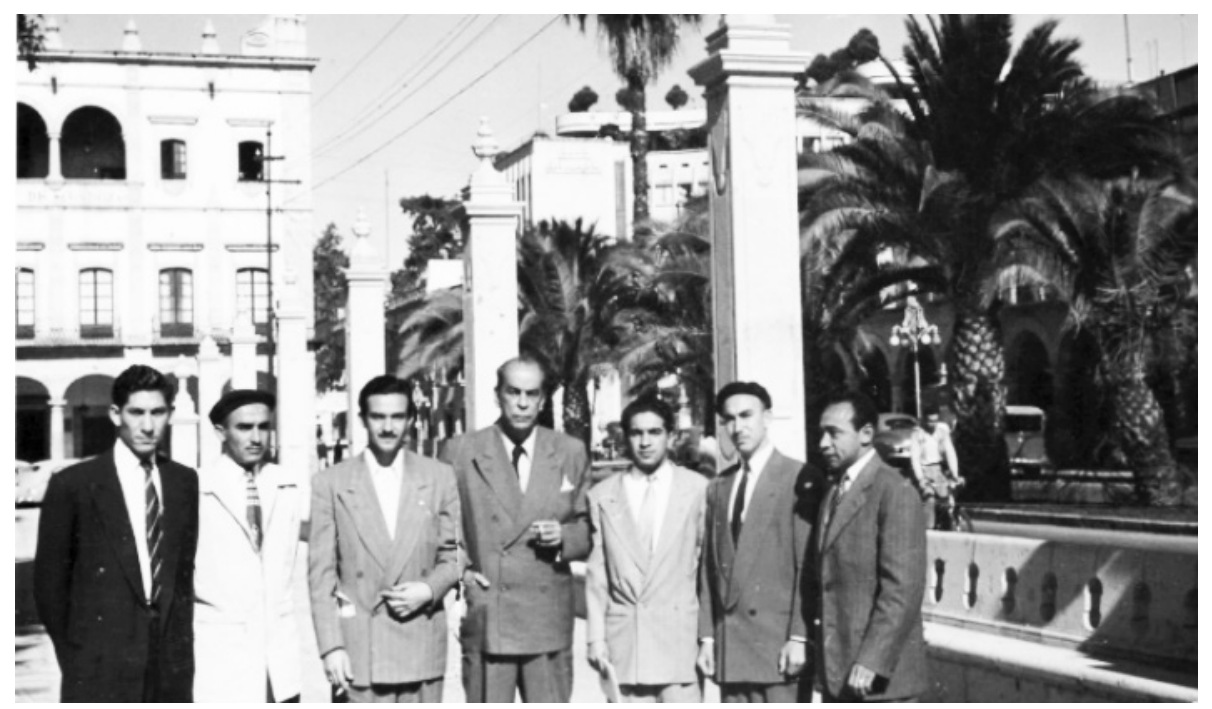

Fuente: Rómulo Gallegos escritor con un grupo de estudiantes venezolanos en el Jardín de los Héroes, Morelia, Michoacán, 1952. 


\section{Introducción}

El objetivo del presente artículo es esbozar un capítulo de la historia del exilio latinoamericano aún no investigado: la vida y las actividades de los grupos de ciudadanos venezolanos que, entre 1928 y 1935 , y entre 1948 y 1958 , fueron opositores o víctimas de los gobiernos que ejercieron el poder nacional en esos momentos, gobiernos no democráticos respaldados por poderosos intereses económicos nacionales y extranjeros; tales opositores, al salir de su país en busca de seguridad y oportunidades, encontraron esas condiciones en los dos países hermanos y vecinos, que fueron los mayores receptores y protectores de exiliados latinoamericanos perseguidos por gobiernos autoritarios y entreguistas de la América del siglo xx: México y Costa Rica.

Descubrir la identidad, vida cotidiana, creación intelectual y su devenir una vez derrocada la dictadura del grupo que se refugió en México en el segundo periodo mencionado es el tema de la tesis doctoral que desarrollo en este momento en el (Instituto de Investigaciones Históricas de la Universidad Michoacana de San Nicolás Hidalgo) en Morelia, Michoacán, México, en un trabajo que he titulado El exilio venezolano en México 1949-1958.
Concebí la inquietud de investigar acerca de este capítulo del exilio al ir profundizando cada vez más en el estudio y en la enseñanza de la historia de nuestro México, de cuya cultura y arte siempre he sido admirador. Topé entonces con un aspecto que también me llenó de orgullo: su importante y noble tradición de acoger y apoyar a personas o grupos de exiliados por razones políticas, tradición que, si bien se remonta al siglo XIX, toma claro vigor en el periodo inmediatamente posterior a la fase armada de la revolución mexicana, al establecerse los primeros gobiernos estables que se reconocieron como revolucionarios, bajo la influencia a mi parecer del ideario latinoamericanista y civilista del cerebro ideológico de la época: José Vasconcelos.

Fue en ese momento en que comencé a frecuentar congresos, coloquios, y eventos culturales que se realizaban esporádicamente para reflexionar y exponer información que ampliaba el conocimiento de esa tradición, organizadó por diversas instituciones académicas de una ciudad cuya vida cultural bien puede compararse en calidad y cantidad con la de las mayores capitales del mundo, y donde decenas de rincones, instituciones y creaciones artísticas nos recuerdan permanentemente a personajes como Trotsky, Mella, Sandino o a tantos ilustres españoles llegados con la 
España trasterrada que de nuevo arribó a América en la primera mitad del siglo XX.

Y fue sólo entonces cuando aprecié en su dimensión y en su valía los comentarios esporádicos de una testigo de uno de esos exilios que tenía siempre a mi alcance y a mi disposición: mi madre, quien, habiendo nacido en Maracaibo, Venezuela, en 1930, llegó a México en 1952 para continuar su carrera de Derecho en la Universidad Michoacana de San Nicolás de Hidalgo, carrera interrumpida, como la de cientos de sus compañeros, por la clausura de la bicentenaria Universidad Central de Venezuela, de Caracas, medida llevada a cabo por un gobierno que consideró, al igual que la dictadura precedente, que esa Universidad era más casa de agitación que de estudio.

En tales comentarios, fui reconociendo la importancia de los personajes célebres que llegaron en ese flujo migratorio; también llamó mi atención la difícil vida cotidiana de los refugiados no famosos, ${ }^{1}$ y me resultó claro que, para completar el conocimiento de la tradición mexicana de que vengo hablando, había que rescatar del olvido a los exilios venezolanos.

1 Recogí estos comentarios en $\mathrm{mi}$ artículo "El exilio venezolano en México en los recuerdos de una protagonista" en Pacarina del Sur, revista en línea, año 6, núm. 22, enero-marzo de 2015. ISSN: 2007-2309 www.pacarinadelsur.com/home/ huellas-y-voces/1088.
Fue ese el momento en que noté que en todos los eventos que presentaban investigaciones sobre grupos o personas llegadas en los diversos exilios, nadie abordaba a los grupos de venezolanos que encontraron apoyo en nuestro país en el siglo $\mathrm{xx}{ }^{2}$ al cuestionar a los participantes de dichos eventos, me informaron dos veces que aun nadie se había adentrado al estudio de los flujos de esa procedencia.

Con el ánimo de contribuir a investigar acerca de esa página pendiente, preparé un anteproyecto de tesis doctoral, que llevé a la universidad que, según lo que he investigado, fue la primera y la que más acogió a estudiantes producto de esa diáspora, para que realizaran o continuaran sus estudios; tras ser aceptado en dicho posgrado, en agosto de 2015, inició formalmente este proceso de investigación.

$\mathrm{Al}$ ir profundizando poco a poco en $\mathrm{mi}$ nuevo tema, pronto me di cuenta de que el grupo de personajes que escapaba de la represión del gobierno establecido de manera violenta e ilegítima en Venezuela encontraba apoyo y refugio, después de México, en otros países, de ellos era con mucho la pequeña Costa Rica el refugio y cuartel de operaciones

2 Hubo tres grupos, flujos o diásporas de ciudadanos venezolanos que, en tres momentos diferentes, encontraron refugio en México durante el siglo XX: en la década de 1920, en 1937 y de 1948 a 1958. Asunto que amplío en el desarrollo del artículo. 
más solicitado. También tuve claro que tales personajes eran compañeros de partido o de circunstancias de los de mi estudio: se trataba del mismo exilio repartido en dos países.

Este artículo pretende tres cosas: presentar someramente a los grupos de opositores venezolanos establecidos en México en esos dos momentos. Anunciar mi compromiso de dar a conocer, en años próximos, un primer trabajo que aborde de manera monográfica y exclusiva a la tercera de las diásporas de ciudadanos venezolanos que dejaron su país en los años mencionados para refugiarse y vivir en México, y, finalmente, hacer un pequeño acercamiento al grupo que, de manera paralela al de mi estudio, se estableció esos años bajo la sombra protectora de la democracia civilista concreta en Costa Rica.

\section{Antecedentes de los exilios para- lelos de exiliados venezolanos re- fugiados en México y Costa Rica}

En el siglo XX venezolano hubo dos gobiernos que han merecido, en todas las opiniones no interesadas que son la mayoría el calificativo de dictaduras: El del general Juan Vicente Gómez (19081935) y el del grupo militar que derrocó al gobierno de don Rómulo Gallegos en octubre de 1948, y gobernó el país hasta enero de 1958, cuyo nombre oficial fueron Junta Militar, que estuvo presidida por los tenientes-coroneles Carlos Delgado Chalvaud, Marcos Pérez Jiménez y Felipe Lovera Páez, y que gobernó del 24 de noviembre de 1948 al 13 de noviembre de 1950. La Junta de Gobierno de los Estados Unidos de Venezuela, presidida por el doctor Germán Suárez Flamerich y los coroneles Marcos Pérez Jiménez y Felipe Lovera Páez que rigió al país del 13 de diciembre de 1950 al 18 de abril de 1953 y la presidencia del coronel y luego general Marcos Pérez Jiménez, quien gobernó el país del 19 de abril de 1953 al 23 de enero de 1958. Los tres gobiernos, pese a sus nombres diferentes, estuvieron respaldados por el mismo grupo de militares y civiles, y gozaron del apoyo de poderosos sectores internos y externos.

Como ambos gobiernos llevaron a cabo prácticas poco democráticas, generaron opositores, los cuales, temiendo por sus vidas en regímenes donde el poder de los gobernantes no tenía límites, debieron salir al exilio, junto con estudiantes y otros ciudadanos que, sin mayor figuración política, debieron seguir a los primeros por razones de dependencia o para continuar sus carreras profesionales, truncadas por los cierres de la principal universidad del país. En ambas ocasiones, Costa Rica y México fueron los principales refugios de estos migrantes. 
Los exiliados bajo la dictadura del general Juan Vicente Gómez

Este dictador, el caudillo más poderoso y cuyo gobierno duró más tiempo en la historia de Venezuela (1908-1935); considerado por el ya citado Vasconcelos quien, aprovechando su legendaria fama de ignorante le apodaba Juan Bisonte, como "El último de los tiranos de la América española, el más monstruoso; el más repugnante y el más despreciable de todos los déspotas que ha producido nuestra infortunada estirpe." ${ }^{3}$ Produjo el primer flujo de exiliados venezolanos que se refugió en los países-refugio mencionados. En México, se trató fundamentalmente de un pequeño grupo de intelectuales no muy conocidos, como Humberto Tejera, Horacio Blanco Fombona hermano del famoso polígrafo Rufino Blanco Fombona, Salvador de la Plaza y Gustavo Machado, entre otros, y un par de militares opositores: los generales Ortega Martínez y Arévalo Cedeño. Algunos de ellos fundaron en tierra azteca el Partido Revolucionario Venezolano después comunista y contribuyeron a crear la Liga Antiimperialista y el Comité Manos Fuera de Nicaragua, e intentaron invadir y liberar Venezuela en dos ocasiones: 1924 y 1931, con apoyo de personajes mexicanos -entre quienes se contó al general Francisco J. Mújica; expediciones similares a la que partiera también desde playas mexicanas, en 1956, hacia Cuba; mas no contaron con la misma suerte.

Y en ese momento álgido, también Costa Rica fue refugio de expulsados de esa misma dictadura. Entre 1931 y 1936, sólo podemos citar en este momento a un exiliado venezolano, Rómulo Betancourt, el líder político más importante del periodo que en la historia de su país conoce como Cuarta República, que cubre de 1959 a 1999.

3 Felicitas López-Portillo, Las relaciones México-Venezuela, 1910-1960: una perspectiva desde la diplomacia mexicana, Morelia, IIH UMSNH / UNAM, 2005, p. 30.

164 Los exilios venezolanos en México y Costa Rica durante el siglo XX.

Andrés Cervantes Varela 


\begin{tabular}{|c|c|c|}
\hline \multicolumn{3}{|c|}{$\begin{array}{c}\text { Cuadro } 1 \\
\text { Presidentes de Venezuela en la Cuarta República }\end{array}$} \\
\hline $\begin{array}{l}\text { Nombre del } \\
\text { Presidente }\end{array}$ & $\begin{array}{c}\text { Años } \\
\text { de Gobierno }\end{array}$ & $\begin{array}{l}\text { Fuerza Política } \\
\text { que lo propuso }\end{array}$ \\
\hline Rómulo Betancourt ${ }^{* 4}$ & $1959-1964$ & Acción Democrática \\
\hline Raúl Leoni* & $1964-1969$ & Acción Democrática \\
\hline Rafael Caldera & $1969-1974$ & $\mathrm{COPEI}^{5}$ \\
\hline Carlos Andrés Pérez* & $1974-1979$ & Acción Democrática \\
\hline Luis Herrera Campíns & $1979-1984$ & COPEI \\
\hline Jaime Lusinchi & 1984-1989 & Acción Democrática \\
\hline Carlos Andrés Pérez* & $1989-1993$ & Acción Democrática \\
\hline Rafael Caldera & 1993-1999 & $\begin{array}{l}\text { Coalición de pequeñas } \\
\text { fuerzas }^{6}\end{array}$ \\
\hline
\end{tabular}

Fuente: elaboración propia

Betancourt fue el fundador del partido político más importante de dicho periodo, Acción Democrática, al que pertenecieron los jefes del Poder Ejecutivo Nacional en cinco de los ocho quinquenios que tuvo la Cuarta República, la mayor parte de los poderes ejecutivos provinciales y de los congresos nacionales y provinciales de esas cuatro décadas, sólo Betancourt fue presidente de Venezuela en dos ocasiones (1945-1948 y 1959-1964).

En mi opinión, se trata de las dos figuras más importantes de los exilios venezolanos en el siglo $\mathrm{xx}$, junto con don Rómulo Gallegos, el novelista más

4 Vivieron en Costa Rica durante su exilio.

5 COPEI: Comité de Organización Popular Electoral Independiente. celebrado de toda la historia literaria venezolana. Si bien Betancourt tenía más importancia política, el liderazgo moral de Gallegos y su prestigio continental eran inasequibles para cualquier otro personaje venezolano del siglo $\mathrm{xx}$.

Gobernaba Gómez con mano de hierro cuando, en febrero de 1928, tuvo lugar La semana del estudiante, un importante movimiento juvenil en la propia Caracas, que debió preocupar al tirano, a juzgar por la reacción represiva que tuvo para el estudiantado universitario.

6 Coalición apodada por el pueblo El Chiripero, reunía al Movimiento Electoral del Pueblo al Partido Comunista, la Vanguardia Socialista y la Causa Radical. 
Una de sus cabezas era Rómulo Betancourt, quien cumplió los escasos 20 años como preso político en una atestada mazmorra, con los grilletes de hierro soldados a las muñecas.

La vida de Betancourt recuerda a la de Martí; es la vida intensa del luchador incansable por la libertad y la democracia en Nuestra América; salió tres veces al destierro, de las cuales, estuvo en dos de esas ocasiones en Costa Rica. En su primer destierro, escapó para la vecina Colombia, de donde hacía periplos por Curazao, Panamá, República Dominicana y Trinidad. En esas giras preparaba, junto con otros jóvenes conspiradores, invasiones armadas para derrocar al astuto y viejo dictador; invasiones que, como las fraguadas desde México, fracasaban siempre.

Entre abril de 1931 y diciembre de 1935 Betancourt radicó en Costa Rica, trabajando como profesor de la Universidad Popular. Allí colaboró en la fundación del Partido Comunista Costarricense, en el cual militó, de hecho fue el director del diario del partido, titulado Trabajo.

Era tan febril su actividad, que en 1933 el gobierno del país emitió una orden de expulsión del vehemente venezolano al ser fichado de comunista. Betancourt no acató la orden y vivió en la clandestinidad.
Quizá la explicación de esa renuencia radica en que en esa época "el otro Rómulo" conoció en esa tierra generosa a la que sería su futura esposa, la costarricense Carmen Valverde, con quien en 1934 contrajo matrimonio y de cuya unión nació su única hija, Virginia Betancourt.

\section{Fotografía 2}

Carmen Valverde de Betancourt, originaria de Costa Rica, Primera dama de Venezuela entre 1945-1948 y 1959-1964.

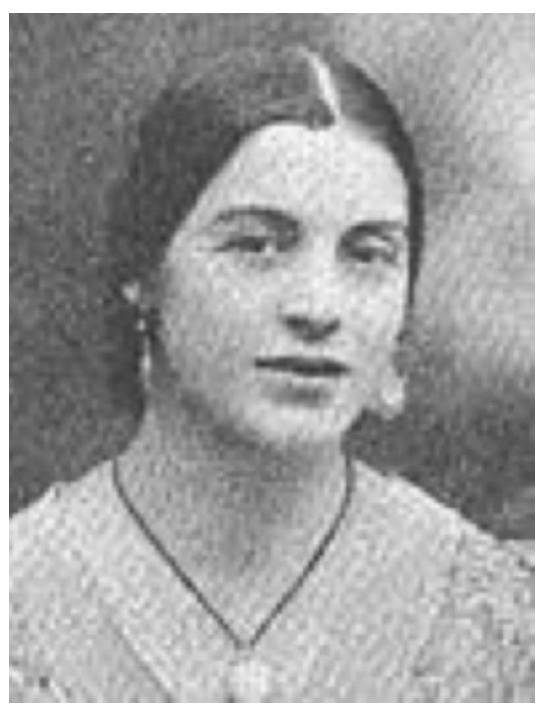

Fuente: Dominio público

7 Apelativo con que se le empezó a conocer a Rómulo Betancourt hacia la tercera década del siglo $\mathrm{XX}$, pues era más famoso don Rómulo Gallegos.

166 Los exilios venezolanos en México y Costa Rica
durante el siglo XX.
Andrés Cervanted Varela


Betancourt regresó a Venezuela el 5 de enero de 1936, semanas después de la muerte de Gómez. Ya en su país, como dijimos, fue el principal fundador del Partido Democrático Nacional, antecedente del partido Acción Democrática; tras competir en la lid electoral contra el general Isaías Medina Angarita, candidato del partido en el poder aun controlado por los herederos de Gómez Betancourt y sus correligionarios $\mathrm{Adecos}^{8}$ comprendieron que por medio de la competencia electoral no iban a lograr conquistar la Presidencia de la República, arrebatándolo al grupo que ejercía el poder desde la muerte de Gómez, ante lo cual se aliaron calladamente con un grupo de oficiales jóvenes del ejército que estaban descontentos entre quienes figuraban los miembros de las futuras juntas militares de los años cincuenta y derrocaron al gobierno presidido por el general Medina en octubre de 1945, confiando a Betancourt nada menos que la presidencia de la República, con el compromiso de hacer una nueva constitución, a cuya potestad debían realizarse elecciones libres en 1947.

En estos comicios los primeros verdaderamente democráticos y por primera vez con voto directo y femenino en la historia del país fue elegido Presidente de la República el famoso novelista Rómulo Gallegos, candidato del partido Acción Democrática.

Sin embargo ese gobierno, que fue el más respaldado por los electores en toda la historia venezolana, sólo duró nueve meses. Los socios militares de Betancourt que en 1945 lo ayudaron a derrocar al general Medina ahora derrocaban al escritor, $\mathrm{y}$, ante las protestas sindicales, populares y estudiantiles, producían un segundo exilio, momento en el cual de nuevo los nombres de Costa Rica y de México resonaron a refugio y libertad para los perseguidos venezolanos.

\section{El exilio venezolano en México entre 1949 y 1958}

El estudio de este grupo de exiliados es, hasta el momento, -a nuestro parecer-, junto con el exilio brasileño que arribó a partir de 1964, el menos estudiado de cuantos flujos de exiliados se establecieron en suelo mexicano durante el pasado siglo.

Al grupo de ciudadanos venezolanos que se establecieron en México entre 1948 y 1958 lo hemos dividido en cuatro subgrupos, en atención a la razón que explica su presencia fuera de Venezuela:

8 Término coloquial con que se conocía en Venezuela a los miembros de Acción Democrática. 
- Ciudadanos venezolanos con antecedentes políticos. Éstos son propiamente los exiliados; sus trayectorias les acarreaban problemas personales con el régimen, por lo que ciudadanos se vieron forzados a hacerlo por razones políticas, eran mayoritariamente miembros de los partidos Acción Democrática $y$, en menor número, del Partido Comunista Venezolano, así como líderes sindicales o estudiantiles de oposición al gobierno golpista. Para casi todos ellos, su libertad y hasta su vida corrían peligro en Venezuela: tenemos documentadas a noventa personas en este caso. ${ }^{9}$

- Estudiantes. Eran personas sin problemas personales con el régimen, pero que, ante el cierre de la principal universidad pública del país, la Universidad Central de Venezuela y ante el clima de represión hacia el estudiantado universitario y en menor medida hacia los liceos opta-

9 Nos hemos apoyado en fuentes bibliográficas, hemerográficas y testimoniales para elaborar esta lista de personas, en constante incremento y del que, naturalmente, cada vez sabemos más. ron por salir a estudiar a México, apoyados en las figuras del primer grupo. Debemos mencionar que una pequeña parte de ellos también tenía afiliación política.

- He encontrado hasta el momento treinta y cuatro estudiantes; veintiuno de ellos incorporados inicial o definitivamente en la Universidad Michoacana de San Nicolás de Hidalgo, en Morelia, Michoacán, institución que, al parecer, fue la primera en recibir estudiantes de este origen de forma masiva, incorporando a la primera oleada de doce estudiantes a mediados de 1952; la integraban diez estudiantes de Medicina de sexo masculino que fueron aceptados en esa facultad, y 2 mujeres, estudiantes de Derecho, que fueron admitidas sin dificultad en la Facultad de Derecho; una de ellas, mi madre.

- Las otras instituciones que acogieron estudiantes de esta procedencia y que tenemos documentados fueron la Universidad de Guadalajara 
y la Universidad Nacional Autónoma de México. ${ }^{10}$

- Familiares de los exiliados. Estos personas tampoco tenían personalmente problemas políticos, mas sí lazos de dependencia económica o familiares con los primeros, lo que explica su presencia en México. Tenemos treinta y tres ejemplos. ${ }^{11}$

- Otros ciudadanos venezolanos que vivieron en México en esos años, pero que no hemos logrado ubicar la causa de su presencia en el país: 5 casos. ${ }^{12}$

Al margen de estos grupos, apareció otro: los hijos de exiliados nacidos en México de matrimonios constituidos por parejas de exiliados y que, a la caída del régimen, regresaron con sus padres

10 Fuentes testimoniales, en los casos de los estudiantes de la UMSNH, confirmados en los expedientes de esos 21 estudiantes existentes en el $\mathrm{Ar}$ chivo, UMSNH, fondo Control Escolar, sección Estudios universitarios, serie: Expedientes de Estudiantes. Con respecto a las otras universidades, nos apoyamos, por lo pronto, sólo en fuentes testimoniales, que esperamos próximamente confirmar con documentos de los archivos de dichas instituciones.

11 Lista armada con testimonios bibliográficos, hemerográficos y testimoniales.

12 Archivo Histórico Municipal de Morelia, Ramo: Extranjeros, Fondo: Documental Independiente II, caja 477. a Venezuela; fuentes de la época calcularon su número en $160,{ }^{13}$ del que tenemos apenas diez nombres, ${ }^{14}$ sin que falte el matrimonio que le puso por nombre a su pequeña hija, nacida en el país refugio, y en circunstancias difíciles, Venezuela. No contamos a otro grupo del que también podríamos incluir varios ejemplos: el de los niños cuyo progenitor o progenitora tenía nacionalidad mexicana.

Si de este conjunto de venezolanos residentes en México, excluimos al último grupo que por el hecho de haber nacido en el país ya eran ciudadanos mexicanos, encontramos que tenemos documentada la presencia de 177 personas, de un millar en que calculan los exiliólogos argentinos Mario Sznajder y Luis Roniger ${ }^{15}$ a los refugiados venezolanos que llegaron a México entre 1949 y1958. Es un grupo pequeño si lo comparamos con el de los asilados chilenos que llegarían al país tras el derrocamiento del presidente Allende que se calculaban en 10000 hasta $1981^{16}$-y entre quienes se contaba la viuda del presidente. El Argentino, originado con el

13 "Homenaje a México de Exiliados Venezolanos", en El Porvenir, Monterrey, Nuevo León, 11 de febrero de $1958,1^{a}$ plana.

14 Fuentes testimoniales.

15 Ver Sznajder / Roniger, La politica del destierro y el exilio en América Latina, pp.192-195

16 Musacchio, Humberto, Diccionario Enciclopédico de México, Ciudad de México, Andrés León Editor, 1989, p. 476, artículo Chile. 
derrocamiento de la presidenta María Estela Martínez en 1975, cuyo flujo se ha calculado en 11000 personas, entre quienes estaba el ex presidente peronista Héctor Cámpora. ${ }^{17} \mathrm{O}$ el uruguayo, de 1976, calculado en 1981 en unos 2000 exiliados en suelo mexicano. ${ }^{18}$

Pese a ser más pequeño, el grupo de mi estudio contó, en mi opinión, con personas no menos importantes: la figura más destacada es con mucho don Rómulo Gallegos, de quien ya hemos hablado y a quien decidieron acompañar 6 de los 13 miembros de su gabinete: Alberto López Gallegos, gobernador del Distrito Federal; Ricardo Montilla, ministro de Agricultura y Cría; Juan Pablo Pérez Alfonso, de Fomento; Eligio Anzola, de Relaciones Interiores; Andrés Eloy Blanco, de Relaciones Exteriores y Gonzalo Barrios, Secretario de la Presidencia de la República. ${ }^{19}$

Mención especial merece Andrés Eloy Blanco, quien, mucho más importante que haber sido canciller, era el poeta más popular y celebrado del siglo xx venezolano $-\mathrm{y}$ acaso de toda la historia

17 Ibid., artículo Argentina.

18 Ibid., artículo Uruguay.

19 Ibid., Rómulo Gallegos, Caracas, Comisión Ejecutiva Nacional para el Centenario de Rómulo Gallegos / Ediciones La Casa de Bello, (Colección Juvenil, núm. 2), 1985, p. 94 literaria del país, ganador de notables premios internacionales, Blanco falleció en un accidente automovilístico en la capital mexicana, durante su exilio; accidente del que huyó su autor material, y que más de uno atribuyó a la sanguinaria dictadura. Blanco, por razones que estamos en trance de esclarecer, está sepultado en el Panteón Nacional, nada menos que cerca del sepulcro del hijo más grande de Venezuela de todos los tiempos, el Libertador de seis naciones: Simón Bolívar.

También creemos importante hacer notar que, entre los mencionados está Juan Pablo Pérez Alfonso, quien, como ministro de Hidrocarburos en el primer quinquenio de la Cuarta República el presidido por Rómulo Betancourt, figuró como uno de dos principales cerebros fundadores y gestores de la Organización de Países Exportadores de Petróleo (OPEP), junto con su homólogo de Arabia Saudita.

Pasando a los estudiantes que fueron a México a hacer o proseguir estudios, es interesante señalar, pese a la imagen de alegre irresponsabilidad que sería fácil atribuirles, en general no vinieron sólo a divertirse, pues casi todos los que hemos 
encontrado alcanzaron la meta que los llevó a México: el título profesional; fueron ingenieros, médicos, abogados. Casi todos volvieron a la patria lejana. Hubo periodistas, escritores; mientras que los que eran miembros de Acción Democrática llegaron a ser congresistas, diplomáticos, ministros de Estado, tenemos documentados hasta ahora a dos gobernadores de Estado; durante la Cuarta República: los médicos Pablo Rafael Salcedo Nadal del Estado Portuguesa y Saíd Raydán, del importantísimo Estado Miranda.

En cuanto a la vida cultural, encontramos ensayistas y escritores que destacaron al regresar a su país, como Germán Carrera Damas, Juan Liscano, Domingo Miliani, Domingo Alberto Rangel, José Manuel Siso Martínez. Entre los académicos, están dos futuros rectores de la Universidad Central: el historiador José Luis Salcedo Bastardo y el médico Rafael José Neri.

Sin embargo algunos de estos estudiantes se quedaron en México -he encontrado ocho en este caso- atados más por razones afectivas que profesionales.
Entre ellos contamos dos médicos, una mujer, dos ingenieros y una abogada, quien sería la primera juez civil no nacida en el país en la historia del Poder Judicial mexicano: mi madre.

\section{Los exiliados venezolanos en Costa Rica, 1948 a 1958}

Ahora debemos ocuparnos de los exiliados que produjo la dictadura de 1948 a 1958 y que se refugiaron en este oasis de paz, en una región tradicionalmente convulsa: la República de Costa Rica.

Gobernaba la paradisiaca nación don José Figueres, con una mentalidad democrática pero no plegada a las órdenes del imperialismo como lo estaban casi todos los gobiernos y las dictaduras que por entonces regían los destinos de América la independencia quedó demostrada con la ausencia del pequeño país en la Conferencia Interamericana de marzo de 1954 que tuvo lugar en Caracas, auspiciada por Foster Dulles, donde se atacó y se buscó atacar al comunismo y a cualquier otra forma de independencia en el continente; la patria de Mora y de Figueres fue la única nación del continente que se excusó de asistir. ${ }^{20}$

20 Freddy Domínguez, y Napoleón Franceshi, Historia de Venezuela contemporánea, Caracas, Ediciones CO-BO, [s/f], p 322. 
Respecto a este grupo, estoy seguro de que se trata de un conjunto bastante similar al que se estableciera en México; Según la opinión de los politólogos Sznajder y Roniger, era más pequeño, y si bien en el caso de mi estudio pude dar cuenta de 177 personas, en el costarricense sólo puedo darla de ocho personajes exiliados allí a los que podríamos sumar sus familiares; un puño de personas, es verdad, pero... ¡Hay que ver su importancia! ${ }^{21}$

Creo que a los avecindados en Costa Rica podemos clasificarlos en los mismos subgrupos en que clasificamos a los avecindados en México. Comencemos, pues, su análisis a partir de los politicos; todos los que hemos encontrado formaban también parte del partido derrocado: Acción Democrática.

Entre estos exiliados de nuevo aparece Rómulo Betancourt, quien pasó alli casi todo su tercer exilio, que duró casi diez años; salió en 1949 hacia Estados Unidos, en donde Washington denunció al régimen golpista ante la Organización de Estados Americanos. A comienzos de 1950, se refugió en La Habana, pero en marzo de 1952, ante el derrocamiento del presidente Prío Socarrás, Betancourt se trasladó a Costa Rica con su familia.

21 Evidentemente, no puedo conocer al grupo asilado en Costa Rica como conozco al que se refugió en México, con el cual he estado vinculado e investigo formalmente desde hace dos años.
El segundo personaje que salta a la vista es Raúl Leoni, preso político desde los 16 años de edad por manifestarse contra Gómez, tras ingresar a la Facultad de Derecho de la Universidad Central en Caracas; fue de los que soñaron con la expedición que preparaba el general rebelde Román Delgado Chalbaud a las costas venezolanas para derrocar al gobierno de Gómez. Desterrado, pasó por Colombia, en donde retomó sus estudios y obtuvo el título de doctor en Derecho. En junio de 1939, regresó a Venezuela para incorporarse a la organización clandestina de Acción Democrática, fuerza política que gobernó Venezuela de 1945 a1948, al cabo de los cuales, al ser derrocado el presidente Gallegos, lo encarcelaron primero, y escapó del país con destino a Cuba. Después pasó por Estados Unidos, en donde se casó, en 1949, con su compatriota América Fernández. Poco después se trasladaron con su hija mayor a Costa Rica, donde tenemos noticia de que nacieron sus otros tres hijos. Posteriormente, tras el derrocamiento del régimen de Pérez Jiménez, la familia Leoni retornó a Venezuela, donde continuó una breve pero brillante carrera que culminó nada menos que en la presidencia de la república.

Y hay un tercer expresidente que se exilió en esa tierra de libertad entre 1952 y 
1958, Carlos Andrés Pérez, lo que explica su identificación con Costa Rica durante su primera gestión presidencial.

También he identificado a otros cinco personajes que, aunque no alcanzaron la celebridad de los mencionados, al luchar contra los opresores de su patria, encontraron como los mencionados fraternal refugio en este país: el primero es Luis Augusto Dubuc Araujo, quien estuvo a cargo del Comité Coordinador de Acción Democrática en el exilio, el cual decidieron establecer en San José. Este comité organizaba reuniones periódicas de los miembros de su partido, a las que asistieron varios miembros establecidos en México y en otros destinos menores. ${ }^{22}$ Encontraron refugio allí también: Pascual Navarro, líder sindical; Antonio Leídenz; Guido Grooscors; Domingo Alberto Rangel; y Mario Briceño Iragorry único militante localizado que pertenecía a un partido distinto a Acción Democrática. ${ }^{23}$ Mientras, Castor Nieves Ríos, militante de Acción Democrática asesinado en Caracas a fines de 1952,24 y Gonzalo Barrios, secretario de la Presidencia de

22 Mario Sznajder, Luis Roniger, La política del destierro y el exilio en América Latina, México, FCE, 2013, pp. 192-195.

23 Diccionario de historia de Venezuela, Fundación POLAR, Caracas, $2^{\circ}$ edición, corregida y aumentada, 1997. (1ª, 1989) 4 vols. ISBN 980-6397-37-i I-p.538

24 "Nuevos sangrientos sucesos en Venezuela", La Voz de Michoacán, sábado 18 de octubre de 1952, p. 1 y 2. la República, alternaron sus años de exilio entre México y Costa Rica. ${ }^{25}$

A estos personajes debieron acompañarlos sus familias, y, en cuanto a los estudiantes, ¡no concibo que no haya habido estudiantes venezolanos matriculados en la Universidad de Costa Rica!

También estoy seguro de que la sociedad y la academia costarricenses apoyaron material y moralmente -como ocurrió en México- al exilio venezolano; prueba de ello es el Doctorado Honoris Causa con que en 1951 la Universidad Central de Costa Rica honró a don Rómulo Gallegos. ${ }^{26}$ Era la tercera universidad del mundo que honraba al escritor con semejante distinción, pero la primera que lo hacía estando el novelista en el exilio.

Un hecho insólito, de esos que abundan en la historia de Nuestra América, es el que rememora el historiador venezolano Gustavo Salcedo, quien atribuye el intento de los dictadores Somoza y Pérez Jiménez por derrocar a Figueres en Costa Rica, en 1955, al apoyo que don Pepe daba a los opositores de esos regímenes:

25 Ver Rómulo Gallegos, op. cit., p. 94

26 CATALÁ, José Agustín Rómulo Gallegos, La segura inmortalidad, Caracas, Ediciones Centauro, 1984, 103 pp. 
El 11 de enero un grupo de aproximadamente quinientos hombres, partiendo de Nicaragua ocupan La Cruz y atacan Villa Quesada en Costa Rica. Bien temprano al día siguiente, aviones de guerra AT-6, provenientes de Nicaragua y, según algunos testigos, portando la bandera de Venezuela y las insignias de su Fuerza Aérea, bombardearon y ametrallaron la capital San José. ${ }^{27}$

Invitamos, pues, a los estudiosos de Nuestra América a realizar una investigación a fondo de esta página pendiente, que ha de completar el conocimiento de la tradición de asilo que, como la de México, supo forjar la pequeña pero grande Costa Rica en el pasado siglo; investigación que esperamos quienes estudiamos el exilio latinoamericano, y que será complemento de la investigación que hoy este servidor desarrolla.
Figura 1.

Giraluna, su último poemario

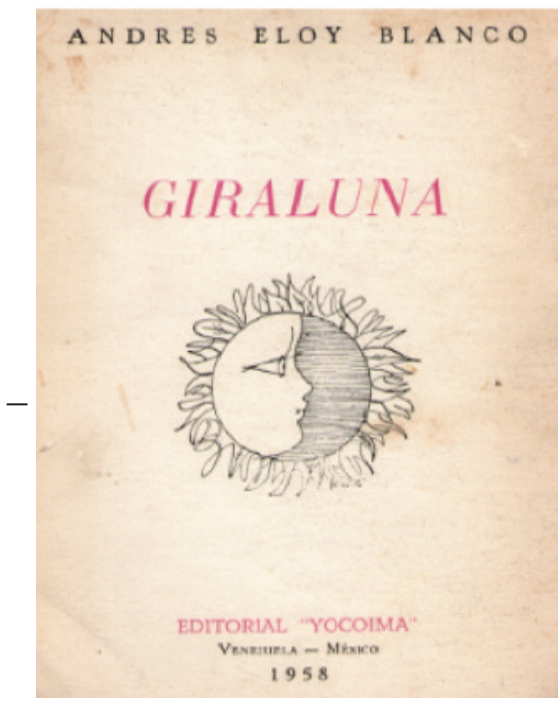

27 Gustavo Enrique Salcedo Ávila, Conflictos en el Caribe: Einsenhower y Pérez Jiménez, historia de cooperación y enfrentamiento. Revista Politeia, núm. 48, vol. 35, Instituto de Estudios Políticos, UCV, 2012:33-62. 
Figura 2

Revista Humanismo, donde colaboraron diversos exiliados venezolanos y Tierra bajo los pies, la única novela de Rómulo Gallegos que se desarrolla en México, publicada de manera póstuma.

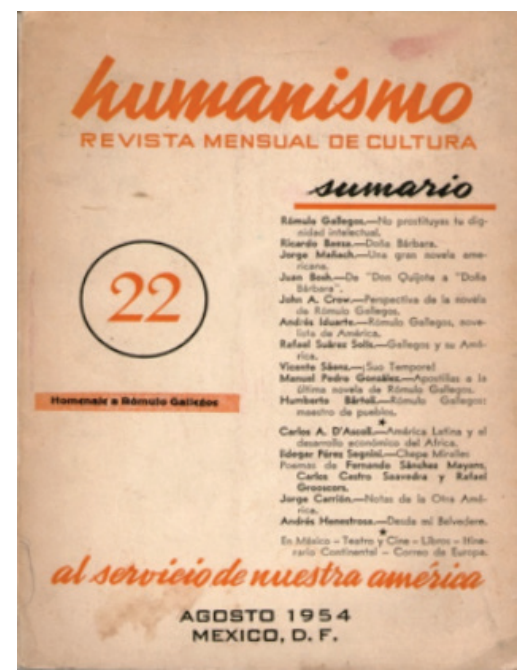

Figura 3

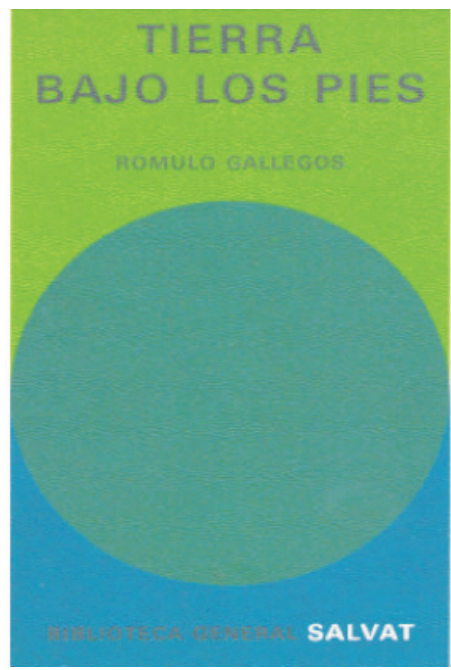

